\title{
Estimation of duration of earthwork with backhoe excavator by Monte Carlo Simulation
}

\author{
B. Sağlam, Ö.H. Bettemir* \\ Inonu University, Department of Civil Engineering, Malatya, Turkey
}

\begin{abstract}
An excavator is a construction machine that is used at constructions which involve earthworks. Pallet or wheeled ones are preferred according to the site conditions. When choosing an excavator, the unit cost of the excavation and the duration of the excavation task play an important role. There are various factors that affect efficiency of the excavator and speed of the excavation. Factors such as bucket volume of the excavator, bucket fill rate, cycle time, swing angle, type of excavated ground, as well as environment and weather conditions influence the performance of the excavators. In this study, software which estimates duration of the excavation and number of required trucks by considering different ground and environmental conditions is developed. Moreover, the software takes hauling distances and job conditions into account. The developed software calculates statistically the effect of the uncertainties in the input parameters from the randomly generated numbers by the Monte Carlo Simulation method. The software is developed by $\mathrm{C}++$ programming language. Developed software can be helpful for the state institutions and private firms to determine the risks of the time and cost estimates.
\end{abstract}

\section{Keywords}

Cost analysis; Sensitivity analysis; Monte Carlo Simulation; Earthwork; Uncertainty

Received: 26 May 2018; Accepted: 30 June 2018

ISSN: 2630-5771 (online) @ 2018 Golden Light Publishing All rights reserved.

\section{Introduction}

There are many input parameters in the excavation works that affect the duration of the excavation activity. The uncertainties of these parameters are often neglected by the contractors and a reliable risk analysis of the excavation cannot be performed. However, if a proper risk analysis is carried out, it will reveal that serious deviations may occur in the end of the excavation work. For example, it is very important to determine the suitable excavator to be used according to the ground conditions to be excavated. In order to be able to properly analyze the risk of construction work, where earthwork is intensive, all parameters affecting the excavation speed of construction machines need to be correctly modeled and analyzed.

Šalinić et al. have proposed an idea to obtain a differential motion equation involving digging, lifting and recycling processes with the effect of ground foundation deformability in order to obtain a more efficient approach in the analysis of excavator dynamics in terms of computational efficiency [1]. For the excavator, they constructed the differential motion equations using Kane's equations. The proposed equations make the analysis of excavator dynamics possible during execution of tasks such as digging, lifting and trimming.

\footnotetext{
* Corresponding author

Email: onder.bettemir@inonu.edu.tr
} 
Yoon et al. described the spatial factors which affect the loading operation and investigated the different types of motion of the machine [2]. Two basic hypotheses have been examined to confirm the relationship between loading time and spatial factors. To verify the hypotheses, three excavator studies were conducted under different conditions of spatial factors. To analyze the relationship between the spatial factors and the required loading time, the authors broke down the loading operation in accordance with the motion and time flow. The motivation of the research was to improve the productivity of an autonomous excavator developed in Korea. It aims to provide effective working conditions for loading operations.

Zhong et al. focused on the construction timecost-quality trade-off for the planning or design phase, built on static empirical data, and proposed a dynamic time-cost-quality trade-off (DTCQT) method to balance time, cost, and quality at any stage of the construction process [3]. They analyzed the project of building a rockfill dam showing the applicability of the method, and compared the efficiency of the proposed optimization method with that of the linear weighted sum (LWS) and non-dominated sorting genetic algorithm (NSGAII).

Cheng et al. proposed a hybrid optimization mechanism that integrates heuristic algorithms (HAs) and genetic algorithms (GAs), named as heuristic genetic algorithms (HGA), to efficiently generate the resource combination that produces the optimal system performance [4]. Case study showed that this hybrid mechanism, along with the implemented computer program, can efficiently and accurately generate the optimal solution to help construction engineers streamline the planning process of construction operations.

Akkoyun and Ergene have developed software for simulating the properties of two different excavators such as bucket volume, total working time, specific excavation force, unit cost with a dynamic, discrete and stochastic model, comparing the results and determining which excavator would be suitable [5].
During the excavation, the height of the boom must be well controlled so that the bucket teeth can be moved horizontally. While routine depth verification work is being minimized, depth controlled excavation work increases excavation efficiency. The excavation control system created by Haga et al., calculates the bucket tooth position with the signals provided by the installed sensors [6]. In addition to this, it calculates the speed of bucket movement. Thus, more efficient depth control mechanism has been achieved with this system.

In order to keep the cost of the excavation low, suitable excavator and truck fleet should be allocated. Calculation of conformity is done by trial and error and takes considerable endeavor. For this reason, systematic computerization of conformity calculations will considerably reduce the workload of construction planners. In this study, an application was developed that calculates the uncertainty of the duration of a user defined excavation task. Moreover the developed software computes the required and the number of trucks and predicts the risk of a particular finish time by Monte Carlo method.

\section{Method}

In this study, some of the excavator and truck models commonly used in construction sites are defined in the developed software with their technical specifications, and the user is asked to choose which model to use. Then, the duration of work and the number of necessary trucks are calculated. Duration of excavation in terms of hour is calculated by the procedure explained below [7, 8].

$Q=q_{h} * k_{d} * \frac{3600}{C_{S}} * k_{\alpha d} * k_{e}$

In Eq. (1), Q represents the hourly excavation in terms of loose volume, $q_{h}$ represents bucket volume in cubic meter, $k_{d}$ represents bucket fill factor, cycle time is represented by $c_{S}$ in second, $k_{\alpha d}$ represents swing depth factor, and $k_{e}$ is the job efficiency.

The completion time of excavation is calculated by the formula given in Eq. (2): 
Excavation Area x Excavation Depth

Excavated Bank Ground Amount

The number of trucks needed is calculated by the formula given in Eq. (3):

Number of Trucks $=\left(t_{l}+t_{d}+t_{h}+t_{s}\right) /\left(t_{l}\right)$

$t_{l}=$ Truck Loading Time

$t_{d}=$ Truck Dumping Time

$t_{h}=$ Truck Hauling Time

$t_{s}=$ Truck Spotting Time

The work completion time is calculated for 1000 different scenarios created with random numbers generated by considering the uncertainty of the input parameters. A probability distribution function is established according to the obtained work completion times. The probability of achieving the target work completion time from the obtained probability distribution function is estimated by using the Z-table. Probability values of the z-table are entered to the software and the probability of the required event is estimated by interpolation within given probability values.

\section{Examined parameters}

\subsection{Bucket volume}

The bucket volume refers to the volume of the bucket at the front of the excavator. The bucket volume is calculated as the volume in which the soil acts like liquid and will settle in the bucket before overflowing. The bucket volume is determined as the bucket volume of the model selected from the excavators defined in the program. The user chooses the excavator model and the bucket volume is determined by software based on Table 1 according to the selected excavator.

Table 1. Bucket volume values of excavator models

\begin{tabular}{cc}
\hline Excavator Model & Bucket Volume $\left(\mathrm{m}^{3}\right)$ \\
\hline HMK370LC & 2.0 \\
HMK300LC & 1.5 \\
HMK220LC & 1.0 \\
HMK140LC & 0.6 \\
HMK200W & 0.9 \\
HMK140W & 0.6 \\
\hline
\end{tabular}

The bucket volume is a precisely defined parameter and has been introduced to the system so that it does not vary in Monte Carlo analysis because it does not have any ambiguity.

\subsection{Swing angle}

The swing angle is the angle of rotation that the excavator must do to load the truck with the excavated the earth. The angle is measured between the actual excavation site and the dumper truck. The increase in the angle of rotation increases the cycle time. The swing angle is a parameter that will be determined by the user in the area to be excavated and used during the determination of the Swing Depth Factor. The swing angle depends very much on the geometry of the excavation area. It is highly dependent on the docking position and maneuver of the trucks. The uncertainty in the swing angle does not affect the cycle time alone. The maximum depth to which the excavation depth can be acquired by the work machine also affects the cycle time. For this reason, the swing angle is considered together with the excavation depth ratio in Monte Carlo Simulation, together with the uncertainty of excavation depth within the swing depth factor input parameter.

\subsection{Useful load capacity of truck}

Vehicles are not allowed to exceed a certain weight when using highway. The total weight of the truck consists of its own empty weight, the weight of the damper and the weight of the excavated earth. The empty weight of the truck is obtained from the factory data. Damper weight was found by researching in industrial facilities. The dumper weight is set at 4,500 kg for 3-axle trucks and 6,000 $\mathrm{kg}$ for 4-axle trucks. The useful load that a truck can carry is equal to the allowed weight minus the weight of the empty truck and the weight of the damper. The allowed weight is calculated according to the limits determined by the highway if the truck is traveling on the highway. The allowed weight is calculated according to the maximum total weight specified by the factory if the truck is moving offroad. In this study, the useful load capacity of the truck is determined from the model selected from 
the trucks, as shown in Table 2. The truck's useful load capacity is a precisely defined parameter and has been introduced to the system in such a way that Monte Carlo analysis does not show any variability because it does not involve any ambiguity.

\subsection{Bucket fill factor}

The amount of fill of the excavator bucket varies according to the soil class. As a result of observations made in the building sites, bucket fill factor tables were formed by using the tables obtained by observing the cycles of the excavator bucket for various ground classes. In this study, the kd bucket fill factor given in Table 3 is introduced to the software. The type of soil to be excavated is requested from the user and the bucket filling factor corresponding to the floor type is determined accordingly. The bucket fill factor is influenced by the operator's experience, visibility conditions and environmental conditions as well as the ground type. For this reason, it is an input parameter that has significant uncertainty. The bucket fill factor is specified as the input parameter with7\% variability.

Table 2. Truck’s useful load capacities

\begin{tabular}{ccc}
\hline Truck Model & $\begin{array}{c}\text { Useful Load } \\
\text { Capacity (kg) } \\
\text { (Highway) }\end{array}$ & $\begin{array}{c}\text { Useful Load } \\
\text { Capacity (kg) } \\
\text { (Off The Highway) }\end{array}$ \\
\hline 2529KL & 12490 & 16090 \\
3029K & 12960 & 20460 \\
3340K & 12485 & 19985 \\
4140B & 15500 & 24500 \\
1833D & 6408 & 6408 \\
2533D & 11781 & 12781 \\
3233SD & 17671 & 17671 \\
3542D & 10087 & 18087 \\
4142D & 14418 & 21418 \\
\hline
\end{tabular}

Table 3. Bucket filling factors for excavators and loaders

\begin{tabular}{lc}
\hline Material & Bucket Filling Factor \\
\hline General Floor & $0.85-1.10$ \\
Sand and Gravel & $0.90-1.05$ \\
Firm Clay & $0.75-0.95$ \\
Soft Clay & $0.65-0.90$ \\
Rock, well blasted & $0.65-0.85$ \\
Rock, poorly blasted & $0.40-0.65$ \\
\hline
\end{tabular}

\subsection{Swelling factor}

The Swelling Factor is a coefficient that expresses the ratio of the volume of ground removed from its natural site to its volume after digging. This factor is always greater than 1 and the values according to the feature of excavated floor are given in Table 4. The swelling factor is also defined to the software. The feature of the ground to be excavated is requested from the user and the swelling factor is determined by the software. The swelling factor is affected by uncertainties such as heterogeneity of the ground structure, environment and weather conditions. For this reason, the swelling factor is set as the input parameter for the Monte Carlo simulation with $10 \%$ variability.

\subsection{Loose unit weight}

The loose unit weight is a coefficient expressing the unit weight of the swollen ground after the excavation. The values of the weight factor are given in Table 4 according to the feature of the ground excavated. Loose unit weights of common soil types are defined to the software. Once the property of the ground to be excavated is defined the user, the weight corresponding to the ground type is determined by the software. Loose Unit Weight is affected by uncertainties such as the heterogeneity of the ground, the environment and weather conditions. For this reason, the Loose Unit Weight is set as the input parameter with $10 \%$ variability.

Table 4. Swelling factor and loose unit weight values

\begin{tabular}{ccc}
\hline Material & $\begin{array}{c}\text { Swelling } \\
\text { Factor }\end{array}$ & $\begin{array}{c}\text { Loose Unit } \\
\text { Weight }\end{array}$ \\
\hline Dry Clay & 1.35 & 1185 \\
Wet Clay & 1.35 & 1305 \\
Dry Soil & 1.25 & 1325 \\
Wet Soil & 1.25 & 1528 \\
Sand and Gravel & 1.20 & 1575 \\
Dry Gravel & 1.12 & 1475 \\
Wet Gravel & 1.14 & 1765 \\
Limestone & 1.60 & 1630 \\
Well-exploded Rock & 1.60 & 1565 \\
Dry Sand & 1.15 & 1340 \\
Wet Sand & 1.15 & 1400 \\
Shale Rock & 1.40 & 1470 \\
\hline
\end{tabular}




\subsection{Cycle time}

Cycle time of an excavator consists of movement of the empty bucket to the bottom of the excavation pit, excavation of the soil, filling the bucket of the excavator, swinging of the beam towards the dump truck, and loading the dump truck [9]. In order to determine the cycle time, the user enters the hardness of the ground to be excavated and the cS cycle time is determined from Table 5 according to the bucket volume of the excavator and the hardness of the excavated soil. Table 5 is added digitally into the software and the cycle time corresponding to the ground hardness and bucket volume is determined by the software. The cycle time is affected by uncertainties such as experience of the operator, visibility conditions, soil formation, environment and weather conditions. For this reason, the Cycle Time is set as the input parameter with $10 \%$ variability.

\subsection{Swing depth factor}

The cycle time obtained from Table 5 depends on the size of the excavator and the hardness of the excavated floor. However, cycle time is also affected by the swing angle and depth of excavation. For this reason, the cycle time is corrected by multiplying with the coefficient called the swing depth factor, kad, which is obtained by considering the swing angle and depth of excavation. The swing depth factor is determined from Table 6 depending on the size of the excavator, swing angle, and depth of excavation.

Output of the excavator can be determined by Eq. (1) when all of the parameters are obtained.

Table 5. Standard cycle time table

\begin{tabular}{cccc}
\hline & $\begin{array}{c}\text { Small } \\
\text { Excavator } \\
<0.76 \mathrm{~m}^{3}\end{array}$ & $\begin{array}{c}\text { Medium } \\
\text { Excavator } \\
0.95-1.72 \mathrm{~m}^{3}\end{array}$ & $\begin{array}{c}\text { Large } \\
\text { Excavator } \\
>1.72 \mathrm{~m}^{3}\end{array}$ \\
\hline $\begin{array}{c}\text { Sand, Gravel, } \\
\text { Soft Soil } \\
\text { Common Earth, } \\
\text { Soft Clay, } \\
\text { Average Soil } \\
\text { Hard Clay, Stiff } \\
\text { Soil }\end{array}$ & 15 & 18 & 24 \\
\hline
\end{tabular}

Table 6. Swing depth factor table for hydraulic excavators

\begin{tabular}{ccccccc}
\hline \multirow{2}{*}{$\begin{array}{c}\text { Depth of Excavation } \\
\text { (Max. Depth Percent.) }\end{array}$} & \multicolumn{6}{c}{ Swing Angle } \\
\cline { 2 - 7 } & 45 & 60 & 75 & 90 & 120 & 180 \\
\hline 30 & 1.33 & 1.26 & 1.21 & 1.15 & 1.08 & 0.95 \\
50 & 1.28 & 1.21 & 1.16 & 1.10 & 1.03 & 0.91 \\
70 & 1.16 & 1.10 & 1.05 & 1.00 & 0.94 & 0.83 \\
90 & 1.04 & 1.00 & 0.95 & 0.90 & 0.85 & 0.75 \\
\hline
\end{tabular}

However, the result of the calculation gives the swollen volume. Bank volume of excavation is calculated by dividing the loose volume by the swelling factor.

Bank Volume $=\frac{\text { Loose Volume }}{\text { Swelling Factor }}$

Duration of the excavation task is calculated by Eq. (5).

Work Completion Time $=\frac{\text { Volume of Excavation }}{\text { Output of Excavator }}$

\subsection{Number of required trucks}

The number of required trucks for excavation is calculated by Eq. (3). Truck Loading Time and Return Time in Eq. (3) are determined by the user, and the Dump Time is 1 and the Spot Time is 2 minutes respectively.

Truck loading time is calculated by the Eq. (6).

$t_{l}=\frac{\text { Capacity } \times \text { Actual Cycle Time }}{\text { Actual Bucket Volume }}$

where,

Actual Cycle Time $=\frac{\text { Cycle Time }}{\text { Swing Depth Factor }}$

Actual Bucket Volume $=$ Bucket Volume

x Bucket Filling Factor

\section{Estimation of excavation duration by Monte Carlo Simulation}

Monte Carlo Simulation is a statistically modeling method for the effect of uncertainties of input parameters on the output parameters. The Monte Carlo Simulation consists of 5 steps [10]. 
In the first step, input parameters with uncertainty as well as, the distribution of uncertainties and the range of the distribution are determined. The input parameters with uncertainty are denoted by xi and probability distribution is assigned for each xi in the first step. In the second step, samples are created from the ranges and the assigned distributions. At the end of this step, $m$ samples are created by generating $n$ random numbers for each sample

$x_{i}=\left[x_{i 1}, x_{i 2}, \ldots, x_{i m}\right], \quad i=1,2, \ldots, n$

In Eq. (9), $n$ is the number of input parameters, $\mathrm{m}$ is the sample size. Choosing the correct sample size is critical. If the sample size is too small, the interaction of the input parameters with each other can not be properly modeled and the effect of the uncertainties can not be fully measured. If the sample size is too large, the modeling will require the use of very high-capacity computers because it will require excessive memory and CPU power. With the creation of random numbers, the second step is completed.

In the third step, input parameters are matched with each other and $\mathrm{m}$ combinations are formed. The formation of output parameters by randomly matched input parameters is shown in Eq. (10).

$y_{i}=f\left(x_{i 1}, x_{i 2}, \ldots, x_{i n}\right)=f\left(x_{i}\right) \quad i=1,2, \ldots, m$

In essence, this model makes a mapping for the input parameters to analyze the uncertainties of the values. The input parameters of $j=1,2, \ldots, n$ are matched for each $x_{i j}$ and $m$ input simulation models are formed by randomly generated numbers for each input parameter according to their probability distribution. The generated models are used to predict the uncertainty of the output by using normal distribution.

In the fourth step, the averages of the $y_{i}$ values of the resulting data set are obtained.

$$
E(y)=\sum_{i=1}^{m} \frac{y_{i}}{m}
$$

In the fifth step, the correlation of the $y_{i}$ values with the standard deviation and the input parameters is calculated.

$V(y)=\sum_{i=1}^{m} \frac{\left[y_{i}-E(y)\right]^{2}}{m-1}$

A normal distribution curve is constructed from the calculated mean and standard deviation values. Risk analysis for a particular result is performed by means of z-table.

\section{Analysis results}

Monte Carlo Simulation is implemented for the estimation of uncertainty of earthwork tasks. Sample size of the simulation is taken as 1000. By using the 1000 results, uncertainty of the estimated duration of excavation as well as sensitivity of input parameters are examined. The excavation pit and dump area is shown in Fig. 1. The data entry process is given in Fig. 2.

The analysis is performed for several construction machines and site conditions. The input data is given in Table 7 .

Analysis results are shown in Table 8. The columns represent the average of the input parameter determined at the end of the sensitivity analysis.

Cycle Time is assumed to be constant with no variation. Therefore, the cycle time column represents the corresponding cycle time values obtained by cycle time table. Swelling factor column represents the average of the swelling factors which are randomly generated by the software. Truck loading time represents the average of the truck loading times obtained by the average of 1000 loading times.

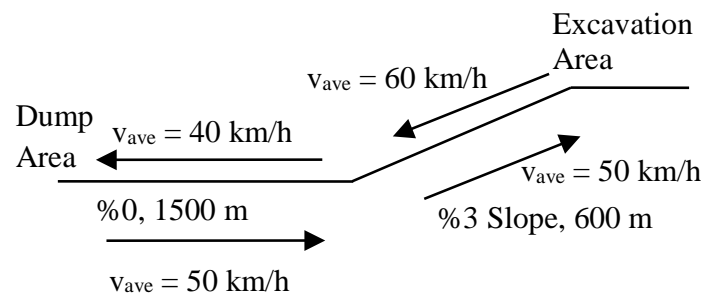

Haul path and average velocities

Fig. 1. Haul path of dump trucks 
Number of required trucks column represents the minimum required number of trucks which will keep the excavator excavate without stopping. That is without waiting for an empty truck to arrive. Work completion time column is the average of the work completion time obtained by the Monte Carlo Sensitivity analysis. The next column represents the standard deviation of the work completion time. Probability of on time completion columns represents the probability of finishing the job earlier than the deadline, which is the target time. The probability is computed by using the z-table. The software interpolates between the nearest two ztable values and provides the computed probability.

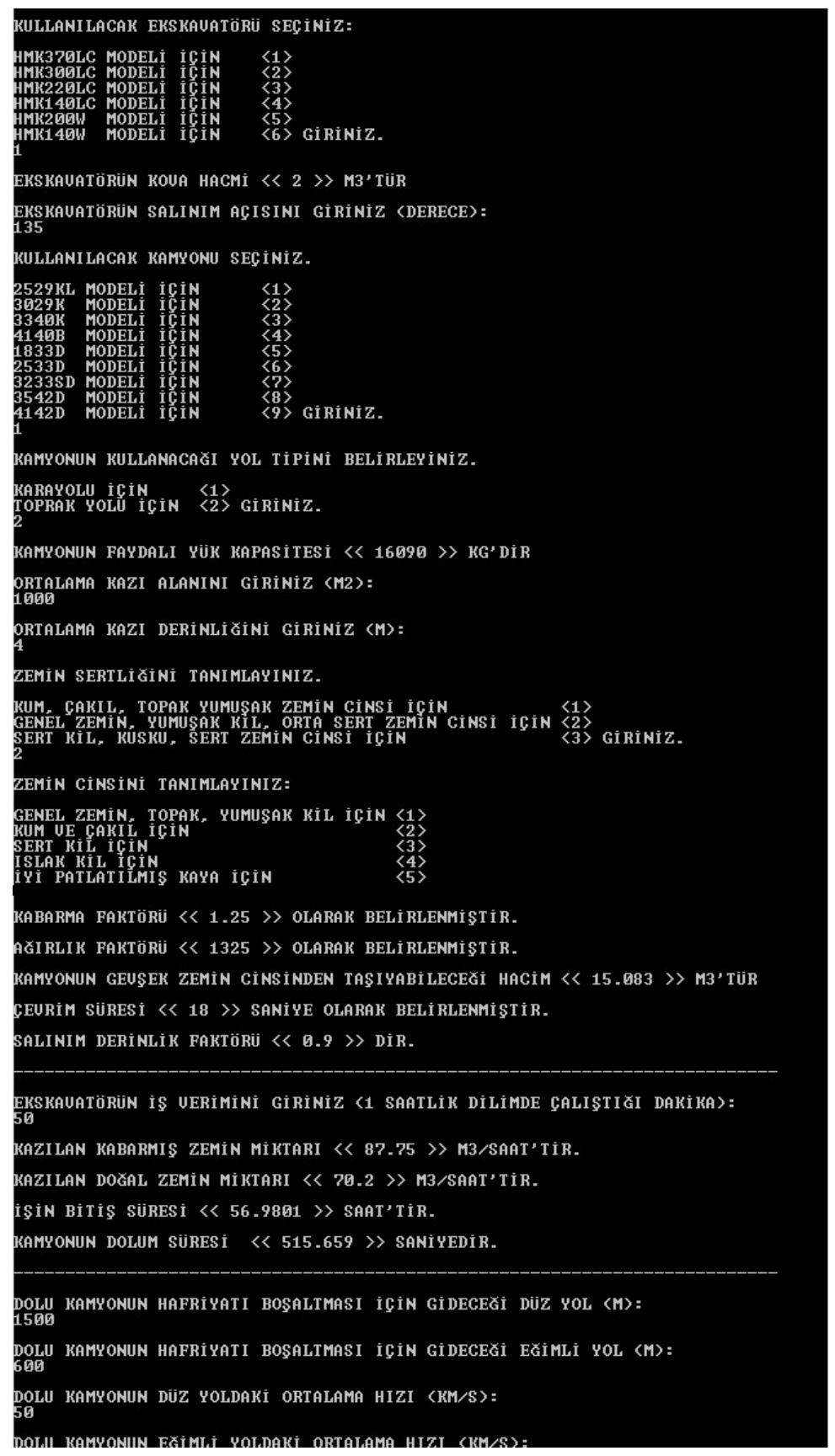

Fig. 2. Haul path of dump trucks 
Table 7. Input values of the sensitivity analysis

\begin{tabular}{cccccccccc}
\hline $\begin{array}{c}\text { Excavator } \\
\text { Model }\end{array}$ & $\begin{array}{c}\text { Swing } \\
\text { Angle }\end{array}$ & $\begin{array}{c}\text { Truck } \\
\text { Model }\end{array}$ & $\begin{array}{c}\text { Road } \\
\text { Type }\end{array}$ & $\begin{array}{c}\text { Excavation } \\
\text { Area(m2) }\end{array}$ & $\begin{array}{c}\text { Depth of } \\
\text { Excavation }(\mathrm{m})\end{array}$ & $\begin{array}{c}\text { Ground } \\
\text { Condition }\end{array}$ & $\begin{array}{c}\text { Ground } \\
\text { Type }\end{array}$ & $\begin{array}{c}\text { Soil } \\
\text { Property }\end{array}$ & $\begin{array}{c}\text { Efficiency } \\
(\mathrm{min})\end{array}$ \\
\hline HMK370LC & 115 & $3340 \mathrm{~K}$ & Off-Road & 4000 & 2.5 & C.E. & General & Dry Soil & 50 \\
HMK300LC & 115 & $3340 \mathrm{~K}$ & Off-Road & 4000 & 2.5 & C.E. & General & Dry Soil & 50 \\
HMK220LC & 115 & $3340 \mathrm{~K}$ & Off-Road & 4000 & 2.5 & C.E. & General & Dry Soil & 50 \\
HMK140LC & 115 & $3340 \mathrm{~K}$ & Off-Road & 4000 & 2.5 & C.E. & General & Dry Soil & 50 \\
HMK200W & 115 & $3340 \mathrm{~K}$ & Off-Road & 4000 & 2.5 & C.E. & General & Dry Soil & 50 \\
HMK140W & 115 & $3340 \mathrm{~K}$ & Off-Road & 4000 & 2.5 & C.E. & General & Dry Soil & 50 \\
HMK300LC & 115 & $2529 \mathrm{KL}$ & Off-Road & 4000 & 2.5 & C.E. & General & Dry Soil & 50 \\
HMK300LC & 115 & $3029 \mathrm{~K}$ & Off-Road & 4000 & 2.5 & C.E. & General & Dry Soil & 50 \\
HMK300LC & 115 & $3340 \mathrm{~K}$ & Off-Road & 4000 & 2.5 & C.E. & General & Dry Soil & 50 \\
HMK300LC & 115 & $4140 \mathrm{~B}$ & Off-Road & 4000 & 2.5 & C.E. & General & Dry Soil & 50 \\
HMK300LC & 115 & 1833D & Off-Road & 4000 & 2.5 & C.E. & General & Dry Soil & 50 \\
HMK300LC & 115 & 2533D & Off-Road & 4000 & 2.5 & C.E. & General & Dry Soil & 50 \\
HMK300LC & 115 & 3233SD & Off-Road & 4000 & 2.5 & C.E. & General & Dry Soil & 50 \\
HMK300LC & 115 & 3542D & Off-Road & 4000 & 2.5 & C.E. & General & Dry Soil & 50 \\
HMK300LC & 115 & 4142D & Off-Road & 4000 & 2.5 & C.E. & General & Dry Soil & 50 \\
\hline
\end{tabular}

Table 8. Results of Monte Carlo Sensitivity Analysis

\begin{tabular}{|c|c|c|c|c|c|c|c|c|c|}
\hline $\begin{array}{l}\text { Cycle } \\
\text { Time } \\
\text { (sec) } \\
\end{array}$ & $\begin{array}{l}\text { Swelling } \\
\text { Factor }\end{array}$ & $\begin{array}{c}\text { Truck } \\
\text { Loading } \\
\text { Time } \\
\text { (sec) }\end{array}$ & $\begin{array}{c}\text { Full Truck } \\
\text { Departure } \\
\text { Time } \\
\text { (min) }\end{array}$ & $\begin{array}{c}\text { Empty Truck } \\
\text { Return Time } \\
\text { (min) }\end{array}$ & $\begin{array}{c}\text { Number Of } \\
\text { Required } \\
\text { Trucks }\end{array}$ & $\begin{array}{l}\text { Target Work } \\
\text { Completion } \\
\text { Time (h) }\end{array}$ & $\begin{array}{c}\text { Work } \\
\text { Completion } \\
\text { Time (h) }\end{array}$ & $\begin{array}{l}\text { Standard } \\
\text { Deviation } \\
\text { (h) }\end{array}$ & $\begin{array}{l}\text { Probability } \\
\text { of On Time } \\
\text { Completion }\end{array}$ \\
\hline 30 & 1.0924 & 212.414 & 3.45 & 2.4 & 4 & 65 & 58.6792 & 1.7966 & 0.9638 \\
\hline 23 & 1.1128 & 213.155 & 3.45 & 2.4 & 4 & 65 & 58.8838 & 1.7462 & 0.9594 \\
\hline 23 & 1.1128 & 319.732 & 3.45 & 2.4 & 3 & 65 & 88.3257 & 4.5582 & 0.0003 \\
\hline 18 & 1.0417 & 445.529 & 3.45 & 2.4 & 3 & 65 & 123.077 & 7.8588 & 0.0003 \\
\hline 23 & 1.1128 & 355.258 & 3.45 & 2.4 & 3 & 65 & 98.1396 & 5.8348 & 0.0003 \\
\hline 18 & 1.0417 & 445.529 & 3.45 & 2.4 & 3 & 65 & 123.077 & 8.2187 & 0.0003 \\
\hline 23 & 1.1128 & 171.612 & 3.45 & 2.4 & 5 & 65 & 58.8838 & 1.7735 & 0.9618 \\
\hline 23 & 1.1128 & 218.221 & 3.45 & 2.4 & 4 & 65 & 58.8838 & 1.7702 & 0.9615 \\
\hline 23 & 1.1128 & 213.155 & 3.45 & 2.4 & 4 & 65 & 58.8838 & 1.7655 & 0.9611 \\
\hline 23 & 1.1128 & 261.311 & 3.45 & 2.4 & 4 & 65 & 58.8838 & 1.6596 & 0.9513 \\
\hline 23 & 1.1128 & 68.3461 & 3.45 & 2.4 & 9 & 65 & 58.8838 & 1.7304 & 0.958 \\
\hline 23 & 1.1128 & 136.319 & 3.45 & 2.4 & 5 & 65 & 58.8838 & 1.7241 & 0.9575 \\
\hline 23 & 1.1128 & 188.474 & 3.45 & 2.4 & 4 & 65 & 58.8838 & 1.7509 & 0.9598 \\
\hline 23 & 1.1128 & 192.911 & 3.45 & 2.4 & 4 & 65 & 58.8838 & 1.6497 & 0.9503 \\
\hline 23 & 1.1128 & 228.439 & 3.45 & 2.4 & 4 & 65 & 58.8838 & 1.6763 & 0.953 \\
\hline
\end{tabular}

\subsection{Bucket filling factor}

Correlation coefficient of the Bucket Fill Factor on the duration of excavation is computed as -0.35 . Duration of excavation decreases as the Bucket Fill Factor increases. The relationship between bucket fill factor and duration of excavation is shown in Fig. 3.

Besides duration of excavation, sensitivity of number of required trucks is also investigated. Correlation of number of trucks and bucket fill factor is 0.39 which represents a strong correlation between the two parameters. The relationship 
between bucket fill factor and number of trucks is shown in Fig. 4.

\subsection{Cycle time}

Correlation coefficient between the Cycle Time and the Work Completion Time is computed as 0.49 . Fig. 5 illustrates that as the cycle time increases, the Job Completion Time increases and the cycle time is observed to have a significant effect on the Work Completion Time.

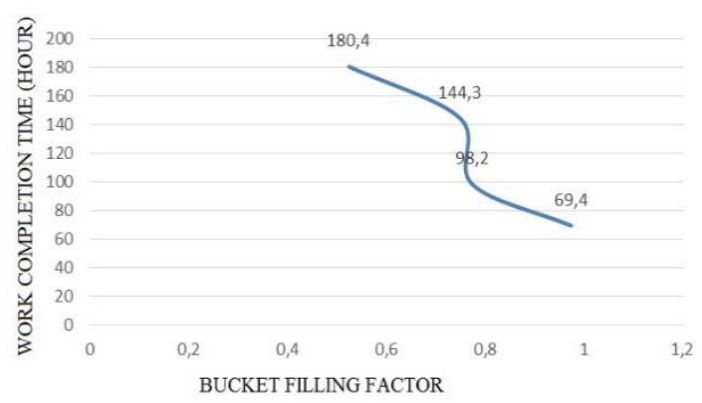

Fig. 3. Relationship between bucket fill factor and duration of excavation

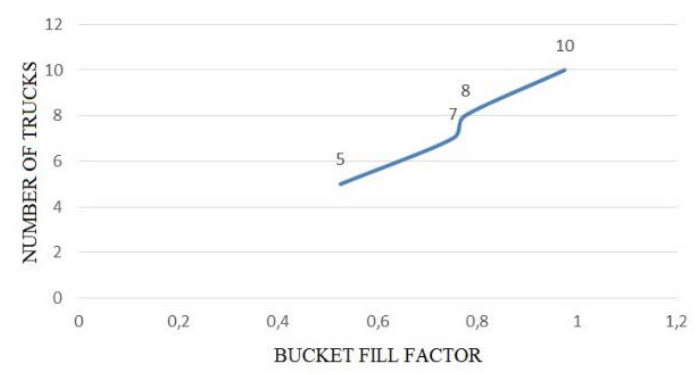

Fig. 4. Number of trucks- bucket fill factor relationship

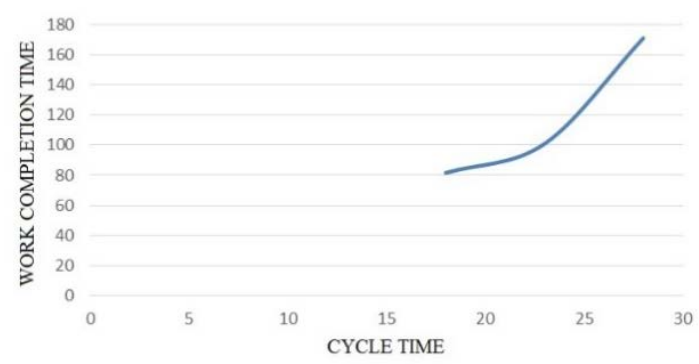

Fig. 5. Work completion time--cycle time relationship
It was also found that the correlation coefficient between Cycle Time and Number of Trucks is 0.45. As can be seen in Fig. 6, number of required trucks decreases when the cycle time increases.

\subsection{Swing depth factor}

At the end of the analysis correlation coefficient of the Swing Depth Factor and duration of excavation is computed as -0.21 . Work Completion Time decreases when the Swing Depth Factor increases which can be seen in Fig. 7.

In addition, correlation between the Effect of Swing Depth Factor and Number of Trucks is examined and the correlation coefficient of the two parameters is computed as 0.26. As seen in Fig. 8, as the Swing Depth Factor increases the number of necessary trucks also increases. The relationship represents a positive correlation between the swing depth factor and the number of trucks.

\section{Conclusion}

Soil work is one of the most important tasks of heavy construction works. The planning and implementation of the excavation work should be analyzed properly. Planning of excavation without detailed analysis can have adverse consequences on the profitability. Often, delays and additional costs are incurred in earthwork, as contractors do not perform a sound risk analysis. It is very important that through the sensitivity analysis the input parameters such as the type of excavated ground, the model of the vehicles to be used, and environmental conditions should be examined appropriately.

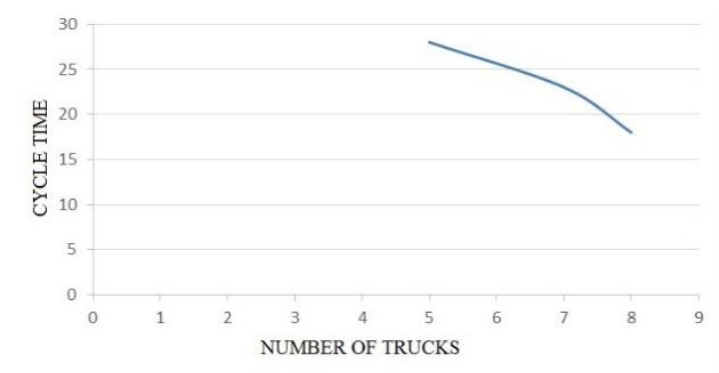

Fig. 6. Number of trucks-cycle time relationship 


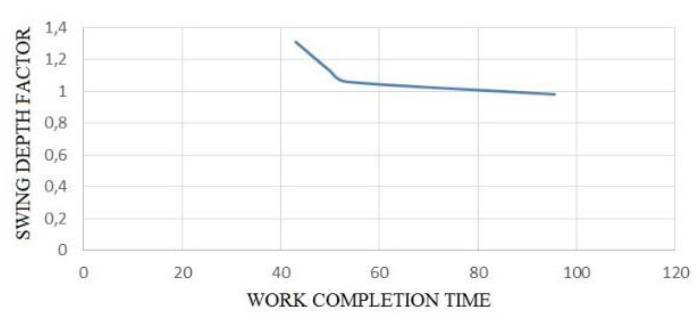

Fig. 7. Work completion time-swing depth factor relationship

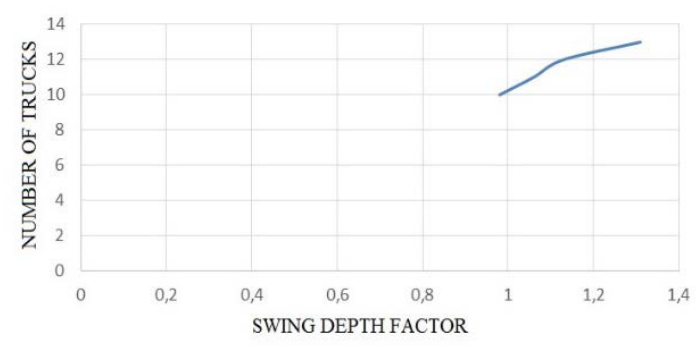

Fig. 8. Number of trucks-swing depth factor relationship

In this study, a computer application which performs risk analysis is developed by using $\mathrm{C}++$ programming language. The developed software determines the probability of completion of the earthwork for a certain deadline. In addition, the effect of input parameters on the work completion time is examined. The presented probabilities can be valuable information for the contractors through the decision-making process.

However, the study has some limitations. The analyzed uncertain input parameters do not represent the whole uncertainty. Weather conditions, job conditions and psychological conditions may also contribute to the total uncertainty. Effect of weather changes with respect to the season of construction and climate of the region. Weather condition can be handled more precisely by a Geographic Information System based application. Moreover, the input parameters can be correlated with each other. Job efficiency and cycle time can be given example to this situation. In this case the random numbers should be generated according to the correlation coefficient matrix of the input parameters.
Otherwise, the Monte Carlo simulation would not provide dependable predictions.

The developed software is freeware therefore it can be obtained without any expense. Another advantage of the software can be introduced as its simplicity that no probability knowledge is required from the end users. Consequently, contractors can easily use this software. The software is fast and can run on any windows PC.

\section{References}

[1] Šalinić, S., Bošković, G., Nikolić M. Dynamic modelling of hydraulic excavator motion using Kane's equations. Automation in Construction 44 (2014) 56-62.

[2] Yoon, J., Kima, J., Seo, J., Suh, S. Spatial factors affecting the loading efficiency of excavators. Automation in Construction 48 (2014) 97-106.

[3] Zhong, D., Hu, W., Wu, B., Li, Z., Zhang, J. Dynamic time-cost-quality tradeoff of rockfill dam construction based on real-time monitoring. Journal of Zhejiang University-Science A (Applied Physics \& Engineering) 18(1) 2017 1-19.

[4] Cheng, T., Feng, C., Chen, Y. A hybrid mechanism for optimizing construction simulation models. Automation in Construction 14 (2005) 85-98.

[5] Akkoyun, Ö., Ergene, S. N. The development of new simulation based software for excavator selection. 5th International Mining Machinery Symposium, 01-02 October 2015, Eskişehir, Turkey

[6] Haga, M., Hiroshi, W., Fujishima, K. 2000, Digging Control System for hydraulic excavator, Mechatronics 11 (2001) 665-676.

[7] Nunnally, S.W. Construction Methods and Management. 6th edition, Pearson Prentice Hall, USA, 2003.

[8] Peurifoy, R. L., Schexnayder, C. J. Construction Planning, Equipment and Method. 6th edition, McGraw-Hill, USA, 2002.

[9] Yang, J., Edwards, D. J., Love, P. E. D. A computational intelligent fuzzy model approach for excavator cycle time simulation. Automation in Construction 12 (2003) 725-735

[10] Helton, J. C. Uncertainty and sensitivity analysis techniques for use in performance assessment for radioactive waste disposal. Reliability Engineering \& System Safety 42(2-3) 1993 327-367. 